\title{
PARADIGMA SCAFFOLDING:ALTERNATIF PEMBELAJARAN SAINS SEBAGAI STIMULUS SISWA SADAR LINGKUNGANDI SDIT LUKMANUL HAKIM LANGSA
}

\section{Paradigma Scaffolding: Alternative Learning Science As Stimulus Students Construction Linkungandi Sdit Lukmanul Hakim Langsa}

\author{
Rita Sari \\ IAIN Zawiyah Cot Kala Langsa \\ Jl. Meurandeh IAIN Zawiyah Cot Kala Langsa-Aceh \\ *Corresponding author: E-mail: ritasyahrie@gmail.com
}

\begin{abstract}
Abstrak
Paradigma pembelajaran sains di abad 21 ini tidak sekadar menghapal fakta dan memahami konsep namun harus mampu menjelaskan bagaimana membangun keterampilan untuk memecahkan masalah secara bersama-sama. Tujuan penelitian ini adalah untuk mendeskripsikan (1) pemberian bantuan(schaffolding)oleh guru dan siswa kepada siswa lainnya yang masih membutuhkan bantuan dalam proses belajar mengajar, dan (2) mendeskripsikan perilaku siswa setelah pembelajaran usai di SDITLukmanul Hakim Langsa tentang upaya sadar lingkungan. Metode penelitian yang digunakan adalah deskriptif kualitatif. Alat pengumpul data yang digunakan adalah berupa observasi. Hasil penelitian menunjukkan bahwa upaya penanaman pentingnya sadar lingkungan sejak dini harus dilakukan secara simultan dan konsisten oleh semua stakeholder sekolah. Hal yang paling mudah adalah dengan memberikan contoh langsung kepada siswa agar mereka tertarik untuk belajar sains.
\end{abstract}

Kata kunci: Scaffolding, Pembelajaran Sains, Sadar Lingkungan

\begin{abstract}
The 21st century learning science paradigm is not simply recite facts and understanding the concept but should be able to explain how to build skills to solve problems together. The purpose of this research is to describe; (1) the granting of aid (schaffolding) by teachers and students to other students who are still in need of assistance in the teaching and learning process, and (2) to describe student behavior after learning over at the SDIT Lukmanul Hakim Langsa about environmentally conscious efforts. The research is used descriptive qualitative methode. Data collecting tool used is a form of observation. The results showed that the importance of environmentally conscious inculcation efforts early on to be done simultaneously and consistently by all stakeholders of the school. The easiest thing is to provide live examples to the students so that they are interested in learning science.
\end{abstract}

Keywords : Scaffolding, Learning Science, Conscious Environment

How to Cite: Sari, R. 2017, Paradigma Scaffolding:Alternatif Pembelajaran Sains Sebagai Stimulus Siswa Sadar Lingkungan SDIT Lukmanul Hakim Langsa, BioLink, Vol. 4 (1): hal. 24-31 


\section{PENDAHULUAN}

Sains merupakan suatu kumpulan pengetahuan yang diperoleh tidak hanya produk saja, namun mencakup pengetahuan seperti keterampilan, keingintahuan, keteguhan hati, dan juga keterampilan dalam hal melakukan penyelidikan ilmiah. Proses bekerja secara ilmiah tidak hanya sekadar mengumpulkan fakta, membangun teori, atau proses mental dan keterampilan manipulatif. Tetapi lebih daripada itu, sains merupakan cara-cara memahami gejala alam yang terus berkembang. Sains juga merupakan produk dari keinginan manusia untuk berimajinasi. Hal ini menjadi menarik dan menantang terutama bagi manusia Indonesia muda yang ingin ber"IPA".

Fowler (Ahmadi, 2008) menyatakan bahwa IPA adalah ilmu yang sistematis dan dirumuskan, yang berhubungan dengan gejala-gejala kebendaan dan didasarkan terutama atas pengamatan (observasi), sehingga untuk ber"IPA" maka dibutuhkan keterampilan pengamatan, penyimpulan, serta penyusunan teori yang berhubungan dengan gejal-gejala yang diamati dan kemudian mengaitkan dengan berbagai cara.

Sianturi dan Simatupang (2003) menjelaskan bahwa Pembelajaran IPA berorientasi pada penumbuhan sikap ilmiah (Scientific Attitude) dan pengembangan keterampilan proses. Scientific Attitude mengandung dua makna yaitu, attitude to science dan attitude of science. Attitude to science mengacu pada sikap terhadap IPA, sedangkan attitude of science mengacu pada sikap yang melekat setelah mempelajari IPA.
Melalui proses pembelajaran dengan kegiatan yang menyenangkan bagi siswa diharapkan dapat menstimulasi dan menginternalisasikan keterampilan dan kreativitas siswa sesuai dengan potensi yang dimilikinya untuk pengembangan diri. Pernyataan ini didukung oleh pendapat Mulyasa (2005) bahwa proses pembelajaran pada hakikatnya adalah untuk mengembangkan aktivitas dan kreativitas siswa melalui berbagai interaksi dan pengalaman belajar. Isjoni (2007) menambahkan bila menginginkan perkembangan mental yang lebih cepat dapat masuk ke tahap yang lebih tinggi, maka siswa diperkaya dengan banyak pengalaman, dan bahwa kecerdasan individu dapat ditingkatkan hingga batas optimalnya dengan pengayaan melalui pengalaman.

Tugas utama guru seperti yang tertuang pada Peraturan Pemerintah Nomor 14 Tahun 2005 adalah mendidik, mengajar, membimbing, mengarahkan, melatih, menilai, dan mengevaluasi peserta didik pada pendidikan anak usia dini jalur pendidikan formal, pendidikan dasar dan pendidikan menengah. Hal tersebut menjelaskan pentingnya peran guru sebagai seorang yang profesional dibidangnya dalam menyusun perencanaan pembelajaran, melaksanakan pembelajaran serta melakukan penilaian terhadap apa yang telah direncanakan dan dilaksanakannya agar mencapai tujuan pembelajaran yang efektif, efisien, dan humanis.

Terlebih pada abad ke 21 ini, ilmu pengetahuan dan teknologi tumbuh dengan cepat dan berkembang pesat secara tidak terduga. Suyanto (2008) menjelaskan bahwa semua 
Rita Sari, Paradigma Scaffolding : Alternatif Pembelajaran Sains Sebagai Stimulus Siswa

perkembangan yang terjadi di lingkungan, tentu memberi implikasiyang signifikan pada proses pembelajaran di setiap jenjang pendidikan. Pertanyaan penting yang harus dijawab oleh pendidik dan calon pendidik dalam hal ini adalah materi mana yang harus disampaikan dalam kurikulum agar peserta didik dapat memiliki kemampuan yang tidak cepat usang? Jika sekiranya semua materi ingin diajarkan kepada peserta didik, maka tentu saja kita akan kehabisan waktu, dan pasti akan selalu tertinggal dari perkembangan ilmu pengetahuan dan teknologi. Oleh karena itu Suyanto menekankan bahwa proses pembelajaran di tiap-tiap jenjang pendidikan diharapkan dapat menghasilkan lulusan yang menurut istilah Bruner "mampu melakukan" transfer of training dan transfer of principles and attitudes.Transfer keterampilan (transfer of training) akan memfasilitasi peserta didik untuk memanfaatkan apa yang didapatkan dalam proses pembelajaran untuk memanfaatkan atau menyelesaikan masalah riil dalam kehidupan di kelas dan di luar kelasnya. Sementara transfer prinsip dan sikap (transfer of principles and attitudes), merupakan kemampuan untuk melakukan transfer dalam arti yang lebih umum, abstrak, dan kompleks.

Agar mampu bersahabat dengan abad 21 ini, maka guru pelajaran sains tidak hanya memberikan materi dengan pola satu arah saja, atau sekadar tugastugas membaca, merangkum pelajaran atau hanya berfokus pada pengembangan kemampuan praktis dan menguji kebenaran teori-teori terdahulu. Namun guru sains masa depan harus mampu menyiapkan peserta didik untuk menjadi anggota masyarakat masa depan yang melek sains, anggota masyarakat yang mampu berpikir tingkat tinggi, memiliki semangat belajar lebih lanjut, dan menjadi pekerja professional. Guru juga bertanggungjawab untuk memfasilitasi peserta didik dalam belajar tentang bagaimana melakukan imkuiri ilmiah dan menggunakan informasi ilmiah untuk menyelesaikan masalah dan mengambil kesimpulan (Jufri, 2013).

Untuk menjawab hal tersebut, Vygotsky sejak tahun 1962 telah menganggas sebuah konsep pembelajaran zone of proximal development dan scaffolding. Scaffolding adalah sebuah teknik untuk mengubah level dukungan. Selama proses pembelajaran, guru atau teman sebaya yang lebih ahli menyesuaikan jumlah bimbingannya dengan level kinerja siswa yang telah dicapai. Ketika tugas yang akan dipelajari oleh siswa adalah tugas yang baru, maka orang yang lebih ahli dapat menggunakan teknik instruksi langsung. Saat kemampuan siswa meningkat, maka semakin sedikit bimbingan yang diberikan. Vygotsky menganggap siswa punya konsep yang kaya tetapi tidak sistematis, tidak teratur dan spontan. Siswa akan bertemu dengan konsep yang lebih sistematis, logis, dan rasional yang dimiliki oleh guru yang membantunya.

Bruner dan Ross (dalam Sutiarso, 2009) menyatakan bahwa "Scaffolding was developed as a metaphor to describe the type of assistance offered by a teacher or peer to support learning". Maksudnya adalah dalam proses scaffolding 
peranan guru sangat penting, yaitu guru membantu siswa menuntaskan tugas atau konsep pada awalnya tidak mampu dia peroleh secara mandiri. Atau dengan kata lain, peranan guru lebih difokuskan hanya memberikan bantuan berupa teknik/keterampilan tertentu dari tugas-tugas yang di luar batas kemampuan siswa. Ketika siswa dipandang telah mampu melakukan tanggung jawabnya dalam tugas-tugas maka ketika itu guru mulai dengan proses "fading", atau melenyapkan bantuan, agar siswa dapat bekerja secara mandiri.

Vygotsky terkenal dengan pendekatan kontruktivis sosial yang menekankan pada konteks sosial dari pembelajaran dan bahwa pengetahuan itu dibangun dan dikonstruksi secara bersama. Keterlibatan dengan orang lain membuka kesempatan bagi siswa untuk mengevaluasi dan memperbaiki pemahaman mereka saat mereka bertemu dengan pemikiran orang lain dan saat mereka berpartisipasi dalam pencarian pemahaman bersama.

Sehingga karakteristik yang diperlukan dimiliki oleh seorang siswa agar mampu menjalin kerjasama dan bekerjasama dengan teman sebayanya di kelas adalah kecerdasan interpersonal. Gardner menjelaskan (dalam Surya, 2007) bahwa Kecerdasan adalah 1) kemampuan untuk menyelesaikan masalah yang terjadi dalam kehidupan manusia, 2) kemampuan untuk menghasilkan persoalan-persoalan baru untuk diselesaikan, dan 3) kemampuan untuk menciptakan sesuatu atau menawarkan jasa yang akan menimbulkan penghargaan dalam budaya seseorang.
Terdapat sembilan jenis kecerdasan ganda yang dimiliki oleh setiap individu, yaitu kecerdasan ruang dan visual, kecerdasan lisan dan bahasa, kecerdasan matematis dan logis, kecerdasan fisik dan gerak, kecerdasan musik dan ritme, kecerdasan interpersonal, kecerdasan intrapersonal, kecerdasan naturalis, dan kecerdasan ekstensialis. Salah satu jenis kecerdasan yang berkaitan dengan pembelajaran kooperatif adalah kecerdasan interpersonal.

Kecerdasan interpersonal atau sering disebut dengan kecerdasan sosial dapat diartikan sebagai kemampuan dan keterampilan seseorang untuk memersepsi dan menangkap perbedaanperbedaan suasana hati, tujuan, motivasi, dan perasaan-perasaan orang lain yang meliputi tiga dimensi yaitu dimensi social sensitivity, social insight, dan social communication.Komunikasi antar pribadi merupakan unsur yang sangat penting bagi perkembangan psikolgis anak yang sehat.

Johnson seperti yang dikutip oleh Safaria (2005) menyatakan Ada empatmanfaat dari hubungan komunikasi antar pribadi bagi anak, yaitu: 1) komunikasi antar pribadi membantu perkembangan intelektual dan sosial anak, 2) identitas atau jati diri anak terbentuk dalam komunikasi dengan diri sendiri dan lewat komunikasi dengan orang lain, 3) dalam rangka memahami realitas di sekelilingnya, anak melakukan pembandingan sosial untuk memperoleh pemahaman akan dunia sekelilingnya, dan 4) kesehatan mental anak sebagian ditentukan oleh kualitas komunikasi atau hubungan antar pribadi yang terjalin antara anak 
Rita Sari, Paradigma Scaffolding : Alternatif Pembelajaran Sains Sebagai Stimulus Siswa

terutama dengan orang-orang terdekatnya.

Pendekatan konstruktivis seperti pada teori Vygotsky menekankan pada konteks social dari pembelajaran dan bahwa pengetahuan itu dibangun dan dikonstruksi secara bersama (mutual). Keterlibatan dengan orang lain membuka kesempatan bagi murid untuk mengevaluasi dan memperbaiki pemahaman mereka saat mereka bertemu dengan pemikiran orang lain dan saat mereka berpartisipasi dalam pencarian pemahaman bersama, dengan cara ini pengalaman dalam konteks social memberikan mekanisme penting untuk perkembangan pemikiran murid (Santrock, 2008).

Sehingga dari penjelasan di atas, dapat dipahami bahwa dalam membelajarkan sains kepada peserta didik, sedikitnya ada dua faktor yang menjadi fokus yakni kegiatan yang dikemas melalui pendekatan pembelajaran yang menyenangkan bagi siswa dan faktor dari dalam diri siswa sendiri yaitu kecerdasan interpersonalnya untuk membina hubungan dengan teman-temannya.

\section{METODE PENELITIAN}

Penelitian ini menggunakan metode deskriptif kualitatif. Nazir
(2005) menjelaskan bahwa metode deskriptif adalah suatu metode dalam meneliti status sekelompok manusia, suatu objek, suatu set kondisi, suatu sistem pemikiran, ataupun suatu kelas peristiwa pada masa sekarang. Tujuannya untuk membuat gambaran atau lukisan secara sistematis, faktual, dan akurat mengenai fakta-fakta, sifatsifat serta hubungan antar fenomena yang diselidiki.Alat pengumpul data yang digunakan adalah observasi. Observasi dilakukan selama proses pembelajaran dan setelah pembelajaran. Mulai sejak tanggal 4 April - 4 Mei 2017 di SDIT Lukmanul Hakim. Subyek penelitian adalah siswa kelas II yakni kelas An-Nisa. Analisis data menggunakanmetode deskriptif kualitatif dengan memaparkan hasil dari observasi yang dilakukan melalui narasi.

\section{HASIL DAN PEMBAHASAN Deskripsi Data Hasil Observasi}

Observasi dilakukan selama pembelajaran berlangsung di kelas dan di luar kelas. Di dalam kelas, guru menjelaskan mengenai tujuan kegiatan belajar dan kemudian memutarkan video mengenai cara bertanam cabai kepada siswa-siswa. Berikut disajikan data hasil observasi pada hari Rabu, tanggal 5 April 2017 di kelas An-Nisa.

Tabel 1. Observasi Pembelajaran Di Kelas

\begin{tabular}{|c|c|c|c|c|}
\hline \multirow{2}{*}{ No } & \multirow{2}{*}{ Aspek Yang Diamati } & Ket & aksanaan & \multirow{2}{*}{ Catatan } \\
\hline & & \multicolumn{2}{|c|}{ V9 Tidal } & \\
\hline 1 & $\begin{array}{lr}\text { Memberikan } & \text { petunjuk } \\
\text { pemecahan } & \text { masalah }\end{array}$ & $\sqrt{ }$ & & $\begin{array}{l}\text { Petunjuk masih perlu } \\
\text { diulang minimal tiga }\end{array}$ \\
\hline & $\begin{array}{l}\text { dan mengobservasi } \\
\text { kegiatan siswa }\end{array}$ & & & $\begin{array}{l}\text { kali sebab perhatian } \\
\text { siswa masih terpecah }\end{array}$ \\
\hline 2 & Memulai memecahkan & $\sqrt{ }$ & & Siswa antusias dalam \\
\hline
\end{tabular}


masalah dan meminta

siswa untuk mencari

solusi

3

Meminta siswa untuk berkolaborasi dalam memecahkan masalah

4

$\begin{array}{lr}\text { Menjelaskan } & \text { proses } \\ \text { penyelesaian } & \text { masalah } \\ \text { kepada siswa } & \end{array}$

belajar

bersama

kelompok

Siswa sangat antusias

dalam bekerjasama

dalam kelompoknya

masing-masing

$\sqrt{ }$ Guru menyelesaikan

proses penyemaian

benih di kantor tanpa

melibatkan siswa dan

melanjutkan materi

pelajaran
Selama pembelajaran di kelas, terdapat dua catatan yang menunjukkan perlunya peninjauan kembali oleh guru, hasil observasi tersebut yakni (1) pada saat memberikan petunjuk mengenai prosedur penanaman cabai guru hanya sekali menjelaskan, sehingga siswa masih riuh dan bertanya kepada temantemannya mengenai penjelasan guru, dan masih ada beberapa siswa yang belum fokus belajar sebab masih berbicara dengan teman sebelahnya, dan (2) pada langkah ketiga, saat guru meminta siswa untuk berkelompok, siswa-siswa langsung melebur dengan kelompok halaqahnya, dan mereka tampak begitu antusias membantu temannya yang belum memahami penjelasan guru.

Ketika guru meminta siswa untuk mengeluarkan wadah untuk menyemai benih cabai, kelas mulai riuh sebab siswa begitu bersemangat. Guru meminta siswa untuk merendam benih cabai kering dan menempatkannya di wadah berupa botol minuman bekas. Namun kekurangannya adalah guru tidak menjelaskan kepada siswa berapa lama benih harus didiamkan sebelum siap tanam. Kegiatan ini hanya dilakukan oleh guru. Kemudian pembelajaran dilanjutkan dengan materi pelajaran lain.

Tibalah saat yang dinantikan siswa, yakni kegiatan menanam cabai. Setelah benih disemai sekitar 3 minggu yakni tanggal 25 April 2017, kegiatan pembelajaran dilanjutkan dengan menanam benih pada media tanam yang telah dibawa oleh siswa. Kegiatan menanam ini begitu seru, sebab semua siswa berusaha membuat yang terbaik. Mereka memulai kegiatan menanam dengan mengucapkan basmalah, kemudian memasukkan tanah kompos ke dalam wadah tanam, dan memasukkan benih cabai. Tidak terlihat siswa yang berebut, mereka tertib di dalam kelompoknya (setiap kelompok berjumlah 5 orang siswa).

Hal yang unik adalah, terlihat ada seorang siswa yang semangat membawa sekarung pupuk kompos untuk menanam cabai dan pot yang besar. Sehingga akhirnya semua siswa meminta untuk menggunakan pupuk kompos yang dibawa Sy. Dan tanpa berdebat, Sy langsung memberikan kepada semua temannya. Nilai toleransi dan berbagi yang sangat baik ditunjukkan melalui perilaku Sy. 
Pada sesi menanam benih cabai di wadah masing-masing tanpa bantuan guru, guru hanya memberi contoh dan siswa dapat dengan mudah meniru perilaku yang telah diamati mereka. Tidak terlihat perilaku negatif yang mereka tampilkan pada saat membantu teman. Bahkan mereka saling membantu dan saling menyemangati dengan teman satu kelompoknya. Pada hari-hari berikutnya, mereka dengan konsisten menyiram tanamannya masing-masing sebelum masuk kelas.

Semua terlihat mengesankan, sebab didukung oleh guru yang memberikan bantuan (scaffolding) berupa penekanan kepada siswa mengenai hadist-hadist mengenai kebersihan, mengenalkan jargon-jargon kebersihan, dan menjelaskan manfaat menjaga kebersihan bagi diri sendiri. Contohnya, "kebersihan itu sebahagian dari iman", "bersih itu sehat", "jaga sehat mu sebelum sakit mu".

Inti kegiatan pembelajaran ini adalah, perilaku siswa setelah akhir pembelajaran, yakni menjaga lingkungan kelas dan sekolah. Siswa sudah paham benar bagaimana menjaga kebersihan kelas dan lingkungan sekolahnya. Ketika mereka meraut atau menajamkan pinsilnya, mereka melakukannya di kertas kosong yang kemudian kertas tersebut dibuang ke tempat sampah. Mereka bisa meletakkan dan menyusun tas dengan rapi di samping meja duduknya. Apabila ada plastik jajan yang berserak, mereka tanpa diminta memungutnya dan membuang ke tong sampah. Mereka sudah berani menegur siswa lain apabila tidak menjaga kebersihan sekolah. Siswa tampak memahami benar pentingnya kebersihan lingkungan.

Kebersihan lingkungan dan upaya menstimulus siswa sadar lingkungan bersih di SDIT Lukmanul Hakim Langsa telah nampak berhasil dengan hasil maksimal. Terlebih slogan sekolah ini adalah beradab, berilmu, dan bermanfaat. Jadi sejak awal memang siswa telah diajarkan mengenai adab atauetikaberwudhu, etika di toilet, etika saat belajar, etika makan, etika dengan teman, etika dengan guru, dan sebagainya.

Dukungan Kepala Sekolah juga sangat penting bagi upaya siswa sadar lingkungan bersih sejak dini. Beliau pernah menyatakan kepada wali murid, bahwa "bapak, ibu, salah satu usaha memilih sekolah yang baik adalah lihatlah kamar mandi sekolah tersebut...". Hal ini Beliau sampaikan pada kegiatan parenting yang rutin dilaksanakan sekali dalam sebulan. Sehingga upaya guru dalam menanamkan sadar lingkungan sejak dini kepada siswa menjadi lebih mudah, sebab seluruh stakeholder memberikan dukungan pada program ini.

Kebersihan lingkungan merupakan syarat bagi terwujudnya kesehatan, dan siswa yang sehat tentunya akan merasa bahagia dalam proses belajar mengajar di sekolah. WHO (World health Organization)sebagai badan kesehatan dunia menjelaskan bahwa lingkungan sehat adalah keadaan yang meliputi kesehatan fisik, mental, dan sosial yg tidak hanya berarti suatu keadaan yg bebas dari penyakit dan kecacatan. Sehingga dapat dipahami bahwa lingkungan sehat adalah tempat segala 
organisme hidup beserta lingkungan abiotiknya saling mendukung serta produktif memengaruhi organisme itu.

Sehingga dengan perilaku yang telah ditampilkan oleh siswa-siswa tersebut, dapat disimpulkan bahwa, tujuan yang ingin dicapai pada penelitian ini yakni tumbuhnya rasa sadar lingkungan pada diri siswa melalui pemberian bantuan (scaffolding) oleh guru dan siswa telah berhasil dilaksanakan.

\section{SIMPULAN}

Pentingnya menanamkan kepada siswa tentang kebersihan lingkungan melalui pembelajaran scaffolding dan mengupayakan siswa bekerjasama dengan teman sebayanya (sekelas) sebagai upaya mengembangkan salah satu kecerdasan interpersonalnya menjadi lebih bermakna saat semua stakeholder sekolah mendukung secara bersama dan konsisten akan hal tersebut. Mengajarkan makna lingkungan bersih dan sehat melalui pembelajaran di kelas dan melatih keterampilan mereka lebih mudah dengan memberikan pemahaman dan contoh langsung. Contoh langsung inilah yang dimaksud dengan bantuan (scaffolding) dari guru kepada siswa. Selain bantuan yang diberikan oleh siswa kepada teman sekelompoknya pada saat pembelajaran. Sehingga dengan lingkungan yang sehat dan bersih, siswa menjadi lebih aktif dan termotivasi dalam belajarnya, sebab lingkungan kelas dan sekolah mereka nyaman. Dan guru perlu mencari dan menemukan paradigma pembelajaran yang relevan dengan tuntutan ilmu pengetahuan sesuai dengan 5 pilar UNESCO, yakni learning to know, learning to do, learning to be, learning to live together, and learning to believe of God.

\section{DAFTAR PUSTAKA}

Bungin, B. 2010. Penelitian Kualitatif: Komunikasi, Ekonomi, Kebijakan Publik, dan Ilmu Sosial Lainnya. Cetakan Keempat. Jakarta: Kencana.

Isjoni. 2007. Cooperative Learning: Mengembangkan Kemampuan Belajar Berkelompok. Bandung: Alfabeta.

Jufri, A.W. 2013. Belajar dan Pembelajaran Sains. Cetakan Pertama. Bandung: Pustaka Reka Cipta.

Nazir, M. 2005. Metode Penelitian. Cetakan Keenam. Bogor: Ghalia Indonesia.

Santrock, J.W. 2008. Psikologi Pendidikan. Cetakan Kedua. Alih Bahasa oleh Tri Wibowo. Jakarta: Kencana.

Sianturi, P dan Simatupang, Z. 2003. Telaah Kurikulum Berbasis Kompetensi. Medan: Unimed Press.

Safari, T. 2005. Interpersonal Intelligence: Metode Pengembangan Kecerdasan Interpersonal Anak. Yogyakarta: Amara Books. 